\title{
A COMUNICAÇÃO COMO BARREIRA À INCLUSÃO DE ALUNOS COM DEFICIÊNCIA VISUAL EM AULAS DE MECÂNICA
}

\section{Communication as a barrier for including visual handicapped pupils in mechanics classes}

Eder Pires de Camargo ${ }^{1}$

Resumo: O presente artigo encontra-se inserido em um estudo que busca compreender as principais barreiras para a inclusão de alunos com deficiência visual no contexto do ensino de física. Focalizando aulas de mecânica, analisa as dificuldades comunicacionais entre licenciandos e discentes com deficiência visual. Para tal, enfatiza as estruturas empírica e semântico-sensorial das linguagens utilizadas, indicando fatores geradores de dificuldades de acessibilidade às informações veiculadas. Recomenda, ainda, alternativas que se destinam a dar condições à participação efetiva do discente com deficiência visual no processo comunicativo. Conclui afirmando que a comunicação representa a principal barreira à participação efetiva de alunos com deficiência visual em aulas de mecânica, e enfatiza a importância da criação de canais comunicacionais adequados como condição básica à inclusão desses alunos.

Palavras-chave: Deficiência visual. Ensino de Física. Mecânica. Comunicação. Inclusão.

Abstract: This paper is a part of a broader study aiming to understand the main barriers for including visual handicapped pupils in physics' teaching contexts. It analyzes communication difficulties between future physics teachers and visual handicapped pupils during Mechanics classes. It emphasizes the empirical and semantic-sensorial structures of the languages used, indicating factors which produce the accessibility difficulties for the spread of information. It recommends alternatives in order to make possible the effective participation of visual handicapped pupils in the communicative process. It concludes that communication represents the main barrier to the effective visual handicapped pupils' participation in optics classes and emphasizes the importance of creating communicatively appropriate channels as a basic condition for including these students.

Keywords: Visual handicap. Physics teaching. Mechanics. Communication. Inclusion.

\footnotetext{
${ }^{1}$ Licenciatura em Física. Doutor em Educação. Docente, Departamento de Física e Química, Faculdade de Engenharia, Universidade Estadual Paulista (Unesp). Ilha Solteira, SP, Brasil. <camargoep@dfq.feis.unesp.br>
}

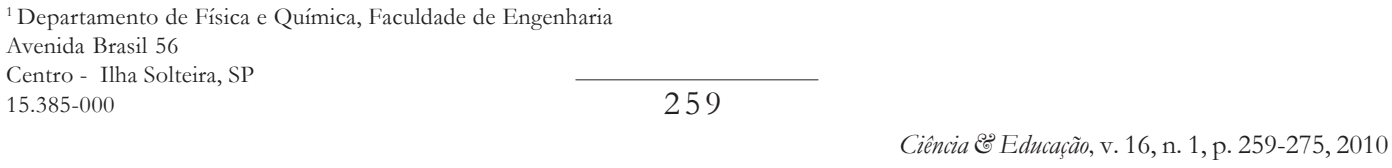




\section{Introdução}

No Brasil, a inserção escolar de pessoas com deficiências (visual, auditiva, física e intelectual) mostra-se prática crescente e de mobilização das bases física e atitudinal, motivadas a partir da LDEBEN 9394/96 (BRASIL,1996). Tal inserção, que por si só não garante a inclusão dos referidos alunos, é positiva na medida em que produz descontentamentos e crises, elementos estes bem-vindos no sentido da busca de alternativas para a adequação social da nova realidade escolar.

Por outro lado, a crise que se estabelece não deve ser analisada de forma unilateral, ou seja, são necessários investimentos nos campos investigativo, de formação docente e de acessibilidade. A caracterização escolar enquanto espaço social orientado pelo respeito e o direito à diversidade nada mais faz do que reconhecer a ontologia humana e sobre ela estruturar-se.

Como argumenta Lacueva (1997), a diversidade é uma vantagem social. A partir dela, os alunos podem relacionar-se e aprender uns com os outros, explorando novas formas de ser e de sentir.

A inclusão norteia-se por valores éticos como: a aceitação das diferenças individuais, a valorização de cada pessoa, a convivência dentro da diversidade humana, a aprendizagem por intermédio da cooperação (SASSAKI, 1999). Efetiva-se por meio de três princípios gerais: a presença do aluno com deficiência na escola regular, a adequação da mencionada escola às necessidades de todos os seus participantes, e a adequação, mediante o fornecimento de condições, do aluno com deficiência ao contexto da sala de aula (SASSAKI, 1999).

Implica, também, uma relação bilateral de adequação entre ambiente educacional e aluno com deficiência, em que o primeiro gera, mobiliza e direciona as condições para a participação efetiva do segundo (MITTLER, 2003). A participação efetiva é entendida em razão da constituição de uma dada atividade escolar que fornece, ao aluno com deficiência, plenas condições de atuação. A participação efetiva, pode, portanto, servir como parâmetro sobre a ocorrência ou não de inclusão, além de explicitar as reais necessidades educacionais do aluno com deficiência.

A compreensão de inclusão como participação efetiva torna-a objetiva, evidenciando as reais dificuldades e viabilidades encontradas por professores e alunos, explicitando variáveis específicas ligadas ao fenômeno educacional e às características da deficiência. Em outras palavras, a ideia de participação efetiva enfatiza as relações: tipo de deficiência/inclusão, características do conteúdo ensinado/inclusão, a utilização de recursos instrucionais/inclusão, tipo de interação docente-discentes/inclusão, perfil comunicativo em sala de aula/inclusão etc.

Nesse contexto, a implantação de ambientes inclusivos deixa de ser abstrata e subjetiva, já que coloca em discussão variáveis específicas tornadas genéricas do ponto de vista teórico (MANTOAN, 2003).

De fato, a inclusão escolar deve orientar-se por princípios gerais como os apontados por Sassaki (1999), e por saberes específicos atrelados ao tipo de deficiência e conteúdo ensinado. A busca por uma didática inclusiva não é simples, deve respeitar e superar os modelos pedagógicos gerais enfatizando o impacto das variáveis específicas na implantação de uma educação para todos. Concluir que incluir alunos com deficiências em aulas de física, química, biologia, matemática, história, língua portuguesa etc. deve ir além dos princípios gerais, é reconhecer a necessidade do investimento em pesquisas que revelem propriedades ativas das variáveis específicas. 
A comunicação como barreira à inclusão ...

No Brasil, realizaram-se pesquisas sobre ensino de física e deficiência visual (CAMARGO, 2005, 2000). Essas pesquisas enfocaram, respectivamente, o tema das concepções alternativas de pessoas cegas de nascimento e a elaboração e condução de atividades para alunos com deficiência visual. Como resultado, indicaram o potencial das percepções não visuais para a construção de conhecimento em física, bem como, um modelo para a atuação docente frente a alunos com deficiência visual.

Entretanto, as pesquisas mencionadas não trataram explicitamente da inclusão do aluno cego e com baixa visão em aulas de física. Por este motivo, vem-se realizando, desde 2005, uma investigação que se destina a compreender quais são as barreiras à inclusão de alunos com deficiência visual em aulas de física (barreiras à participação efetiva desses alunos).

Nessa pesquisa, a primeira etapa identificou viabilidades e dificuldades encontradas por licenciandos para o desenvolvimento de planos de ensino para alunos com e sem deficiência visual (CAMARGO, 2006). A segunda etapa teve por objetivo analisar a aplicação prática desses planos, ou seja, concentra a atenção ao interior da sala de aula que contemplou a presença de alunos deficientes visuais e videntes.

O presente artigo, portanto, indica resultados sobre a aplicação de quatro atividades de ensino de mecânica no contexto educacional descrito. Analisa a comunicação em sala de aula, variável esta que representou a principal barreira para a participação efetiva de alunos com deficiência visual.

Assim, enfoca o fenômeno da inclusão escolar na perspectiva do ensino de mecânica e da deficiência visual, reconhecendo a complexidade do referido fenômeno e a necessidade de recortes e estudos particularizados que enfoquem distintas deficiências e conteúdos escolares.

\section{O contexto das aulas de mecânica}

As quatro atividades do grupo de mecânica ocorreram no Colégio Técnico Industrial Prof. Isaac Portal Roldán (CTI - Bauru). Essas atividades fizeram parte de um curso de extensão denominado "O outro lado da física" oferecido pelo curso de Licenciatura em física da Unesp de Bauru durante o segundo semestre de 2005.

Além de mecânica, o curso contemplou aulas de óptica, eletromagnetismo, termologia e física moderna. A organização para a aplicação dos módulos de ensino ocorreu em duas etapas: momento preparatório e momento de definição do ambiente educacional.

O momento preparatório caracterizou-se por duas atividades básicas realizadas no primeiro semestre de 2005: planejamento de módulos e materiais de ensino e discussão reflexiva de temas inerentes ao ensino de física e à deficiência visual.

No início do primeiro semestre (na disciplina: prática de ensino de física) foi solicitado, aos licenciandos, que se dividissem, aleatoriamente, em cinco grupos de acordo com os temas físicos anteriormente mencionados (planejamento de módulos e materiais de ensino). Assim que os grupos ficaram definidos, foi apresentado a eles o seguinte problema educacional: "Vocês devem elaborar um minicurso de $16 \mathrm{~h}$ sobre o tema físico que seu grupo escolheu, sendo que as atividades de ensino de física constituintes do minicurso devem ser adequadas às especificidades educacionais de alunos com e sem deficiência visual". 
Nos encontros sequentes (discussão reflexiva) foram abordados temas inerentes ao ensino de física e à deficiência visual (CAMARGO, 2005, 2000). Os licenciandos definiram que as atividades constituiriam um curso de extensão a ser oferecido pela Unesp para uma determinada escola da rede regular de ensino de Bauru. A escolha do CTI deu-se por quatro fatores: (a) o CTI é um colégio vinculado à Unesp; (b) existência de boas relações entre a mencionada instituição e a Unesp de Bauru; (c) cursos semelhantes já haviam sido aplicados com sucesso no CTI; (d) proximidade entre o CTI e a Unesp. Tal proximidade facilitou o deslocamento dos licenciandos.

No início do segundo semestre de 2005, os licenciandos iniciaram um período de divulgação junto aos alunos da mencionada instituição. O CTI oferece cursos técnicos de mecânica, eletrônica e processamento de dados, bem como, o Ensino Médio propedêutico. Estudam no CTI alunos da cidade e da região de Bauru com idade média de 15 anos. O número de vagas para a participação dos alunos do CTI no curso "O Outro Lado da Física" foi de 35 , sendo que o número de inscritos foi de aproximadamente setenta alunos. A escolha dos 35 participantes videntes deu-se por sorteio. Dessa forma, os alunos oriundos do CTI e participantes do curso eram provenientes dos três anos do Ensino Médio (profissionalizante e propedêutico).

Paralelamente ao processo de divulgação descrito, entrou-se em contato com a Escola Estadual Mercedes P. Bueno, localizada na cidade de Bauru, a fim de convidar alunos com deficiência visual para participarem do curso anteriormente mencionado. A escola Mercedes foi procurada, pois, no CTI, não havia alunos com deficiência visual matriculados. A Escola Estadual Mercedes P. Bueno possui uma sala de recursos pedagógicos que procura atender às necessidades educacionais de alunos com deficiência visual (ex. ensino do Braile, transcrição de textos ou provas em Braile). Dois alunos com deficiência visual interessaram-se em participar do curso "O outro lado da física". Esses alunos, na ocasião, possuíam as seguintes características em relação à deficiência visual e à escolaridade: ambos eram cegos; um possuía 15 anos de idade e cursava a $8^{a}$ série do Ensino Fundamental (atual nona série), e o outro possuía 34 anos e cursava a oitava série do Ensino de Jovens e Adultos (EJA). O aluno de 15 anos de idade era cego de nascimento e o de 34 perdera a visão aos 24 anos. Para fins organizacionais, o aluno cego de nascimento será identificado neste texto como aluno (B), e o que perdeu a visão ao longo da vida, como aluno (A).

\section{Categoria de análise: Comunicação}

A presente categoria objetiva compreender se os alunos com deficiência visual participaram efetivamente do processo comunicativo das aulas de mecânica, ou seja, se as informações veiculadas pelos licenciandos foram acessíveis a eles. A acessibilidade será avaliada em razão das estruturas empírica e semântico-sensorial da linguagem em comparação com a característica visual dos discentes.

A estrutura empírica refere-se à forma pela qual uma determinada informação é materializada, armazenada, veiculada e percebida (MARTINO, 2005). Organiza-se em função de códigos sensoriais fundamentais e mistos, onde os primeiros representam códigos unitários ou independentes (códigos visual, auditivo, tátil etc.), e os segundos, códigos interdependentes 
A comunicação como barreira à inclusão ...

(audiovisual, tátil-auditivo etc.). Observa-se que os sentidos de natureza olfativa e gustativa não serão, para efeitos de análise desta categoria, considerados como códigos sensoriais utilizados para veiculação de informações. Embora a existência de tais códigos seja possível, entende-se, por hipótese, que, para contextos de sala de aula de mecânica, ela seja desprezível.

A Estrutura semântico-sensorial refere-se aos efeitos produzidos pelas percepções sensoriais no significado de fenômenos, conceitos, objetos, situações e contextos (DIMBLERY e BURTON, 1990). Esses efeitos são entendidos por meio de três referenciais associativos entre significado e percepção sensorial: a indissociabilidade, a vinculação e a não relacionabilidade.

Significados indissociáveis são aqueles cuja representação mental é dependente de determinada percepção sensorial. Esses significados nunca poderão ser representados internamente por meio de percepções sensoriais distintas da que os constituem.

Significados vinculados são aqueles cuja representação mental não é exclusivamente dependente da percepção sensorial utilizada para seu registro ou esquematização. Sempre poderão ser representados por meio de percepções sensoriais distintas da inicial.

Há, para o caso da indissociabilidade, uma relação inseparável entre significado e percepção sensorial, enquanto que, para o caso da vinculação, não.

Significados sensorialmente não relacionáveis (ou sem relação sensorial) não possuem vínculo ou associação com qualquer percepção sensorial. Embora o aprendiz possa construir representações mentais sensoriais acerca de ideias com a presente característica, as mesmas nunca corresponderão de fato aos fenômenos/conceitos que se se destinam comunicar. As representações mentais com a característica semântico-sensorial aqui discutida encontrarse-ão sempre no nível analógico, metafórico e artificial. Trata-se, portanto, de significados abstratos referentes a construtos hipotéticos elaborados para a explicação de fenômenos, efeitos, propriedades etc.

A ideia de "representação" utilizada neste texto é aquela contida em Einsenck e Keane (1991). Segundo os autores, representação é "qualquer notação, signo ou conjunto de símbolos capaz de representar, mesmo na ausência do representado, algum aspecto do mundo externo ou de nossa imaginação". De forma mais específica, a presente ideia fundamenta-se no conceito de "representações internas" ou "representações mentais", que ocorrem no nível subjetivo da cognição, do pensamento. Em outras palavras, tais representações referem-se "às formas em que codificamos características, propriedades, imagens, sensações etc., de um objeto percebido ou imaginado, bem como, de um conceito abstrato" (EINSENCK e KEANE, 1991, p. 202).

Dessa forma, a caracterização das linguagens obedeceu a relação: Linguagem $=($ estrutura empírica) + (estrutura semântico-sensorial).

\section{Procedimentos para a análise}

Todas as atividades foram filmadas e transcritas na íntegra. Constituiu-se, dessa forma, o "corpus de análise". Em seguida, obedecendo aos critérios de análise temática - exploração do material; tratamento dos resultados e interpretação (BARDIN, 1977) - foram identificadas linguagens avaliadas como dificuldade comunicacional entre os videntes e os deficien- 
tes visuais. Esta avaliação foi conduzida pela ideia de acessibilidade dos alunos com deficiência visual às informações veiculadas em sala de aula. A acessibilidade, por sua vez, levou em conta as características da linguagem mediante a "história visual" do discente, ou seja, se ele nasceu cego ou perdeu a visão ao longo da vida.

No processo de exploração do material, realizou-se a fragmentação do corpus de análise (BARDIN, 1977). Para a fragmentação, foram encerrados trechos que continham falas dos participantes caracterizadas pelas mesmas estruturas empírica e semântico-sensorial (mesma linguagem). Em outras palavras, a fragmentação foi orientada pela identificação de um determinado perfil comunicacional utilizado na veiculação de conteúdos de mecânica. Após a fragmentação, realizou-se o agrupamento de dificuldades semelhantes do ponto de vista linguístico. Essas dificuldades serão abordadas no tópico seguinte.

\section{Análise dos dados}

Foram identificadas seis linguagens geradoras de dificuldades de comunicação entre os licenciandos e o aluno (B) e quatro entre os licenciandos e o aluno (A). Para o caso de (B), as linguagens organizaram-se em razão de três estruturas semântico-sensoriais e três estruturas empíricas. São elas: (a) estruturas semântico-sensoriais: significado vinculado às representações visuais, significado indissociável de representações visuais e significado sem relação sensorial; (b) estruturas empíricas: audiovisual interdependente, auditiva e visual independentes e fundamental auditiva. Para o caso de (A), as linguagens organizaram-se em função de duas estruturas semântico-sensoriais e três estruturas empíricas. São elas: (a) estruturas semântico-sensoriais: significado vinculado às representações visuais e significado sem relação sensorial; (b) estruturas empíricas: audiovisual interdependente, auditiva e visual independentes e fundamental auditiva. Na sequência, são tornadas explícitas as características das estruturas mencionadas. Posteriormente, a relação entre tais estruturas e, consequentemente, o perfil linguístico gerador de dificuldade comunicacional serão apresentados e discutidos.

\section{a) Estrutura semântico-sensorial/dificuldade de comunicação}

\section{1) Significados vinculados às representações visuais}

Possuem as seguintes características: (a) são significados registrados por códigos visuais e observados pelo olho; (b) tornam-se, por este motivo, representados internamente por imagens mentais (PAIVIO apud BAJO e CAÑA, 1991); (c) sempre poderão ser registrados e internamente representados por meio de códigos e representações não-visuais. Para as atividades do grupo de mecânica, esses significados foram os seguintes: registros de símbolos de equações físicas, registro de relações matemáticas em equações físicas, indicação de equações, demonstrações de equações físicas, soma vetorial (algébrica e gráfica), indicação de eventos ou propriedades (espaço percorrido, posição do referencial adotado, direção e sentido - velocidade, aceleração, força, quantidade de movimento -, pontos de atuação de forças, decomposição vetorial, registro do sentido de um vetor por ângulos, planos inclinados, trajetórias etc.), forma estrutural de algumas unidades físicas (ex. $\mathrm{m} / \mathrm{s}^{2}, \mathrm{~N} \mathrm{x} \mathrm{m}{ }^{2} / \mathrm{Kg}^{2}$ etc.), características de gráficos (movimentos uniforme e uniformemente variado, força x deformação elástica, energia poten- 
A comunicação como barreira à inclusão ...

cial elástica x deformação etc.), direção e sentido da força centrípeta, ângulo entre força e deslocamento, órbitas e posições de planetas e astros celestes. Significados vinculados às representações visuais estiveram presentes em $96,1 \%$ das dificuldades do aluno (B) e em 99,0\% das dificuldades do aluno (A).

\section{2) Significados indissociáveis de representações visuais}

Somente podem ser registrados e internamente representados por meio de códigos e representações visuais. São exemplos de tais significados: Energia luminosa, Olhar para as estrelas representa ver o passado, frase de Newton: "se enxerguei além dos outros é porque estava no ombro de gigantes". O acesso a fenômenos que contêm esses significados é dependente da observação visual, na medida em que não é possível o registro externo e a representação interna dos mesmos por meio de códigos e imagens não-visuais.

A teoria de Vigotski sobre a cegueira justifica que os significados indissociáveis de representações visuais são inacessíveis às pessoas cegas de nascimento (VIGOTSKI, 1997). Neste sentido, a cegueira nativa em nada se assemelha à sensação visual de um vidente com os olhos vendados, ou seja, o cego de nascimento não vive envolvido na escuridão, já que as ideias de claro, escuro, cores etc., não possuem, para este individuo um significado visual. Os significados indissociáveis de representações visuais estiveram presentes em 2,9\% das dificuldades comunicacionais do aluno (B) e não representaram dificuldade comunicacional ao aluno (A).

\section{3) Significados sensorialmente não relacionáveis}

Suas características estão descritas no tópico Categoria de análise.

A ideia de intervalo de tempo exemplifica este tipo de significado. Representaram $1,0 \%$ das dificuldades dos alunos (A) e (B).

\section{b) Estrutura empírica/dificuldade de comunicação}

\section{1) Audiovisual interdependente}

Caracteriza-se pela dependência mutua entre os códigos auditivo e visual que dão suporte material à veiculação de informações. Do ponto de vista empírico, o acesso às linguagens com esta característica somente pode se dar por meio da observação simultânea dos códigos mencionados, pois, a observação parcial de um dos códigos não desfaz a interdependência de seu suporte material. A estrutura empírica audiovisual interdependente esteve presente em $77,4 \%$ das dificuldades comunicacionais do aluno (B) e em 79,8\% das dificuldades do aluno (A).

\section{2) Auditiva e visual independentes}

Caracteriza-se pela independência entre os códigos auditivo e visual que dão suporte material à linguagem. Ocorre, por exemplo, quando se projetam e falam-se as mesmas informações. Por isto, o nível do detalhamento oral e visual determina padrões de qualidade de acessibilidade às informações veiculadas. Esta estrutura empírica esteve presente em 16,7\% das dificuldades comunicacionais do aluno (B) e em 15,1\% das dificuldades do aluno (A). 
3) Fundamental auditiva: Caracteriza-se por possuir apenas códigos sonoros. $\mathrm{O}$ acesso às linguagens com esta estrutura empírica dá-se por meio da observação auditiva dos mencionados códigos (único suporte material). Esta estrutura empírica esteve presente em $5,9 \%$ das dificuldades comunicacionais do aluno (B) e em 5,0\% das dificuldades do aluno (A).

A Tabela 1 explicita as estruturas empírica e semântico-sensorial das linguagens geradoras de dificuldades comunicacionais ao aluno (B), suas relações e respectivas quantidades.

Tabela 1. Dificuldades de comunicação inerentes ao aluno (B): estruturas empírica e semântico-sensorial das linguagens.

\begin{tabular}{lcccc}
\hline \multicolumn{1}{c}{$\begin{array}{c}\text { Empírica (direita) } \\
\text { Semântico-sensorial (abaixo) }\end{array}$} & $\begin{array}{c}\text { Audiovisual } \\
\text { interdependente }\end{array}$ & $\begin{array}{c}\text { Auditiva e visual } \\
\text { independentes }\end{array}$ & $\begin{array}{c}\text { Fundamental } \\
\text { auditiva }\end{array}$ & $\begin{array}{c}\text { Total } \\
\text { horizontal }\end{array}$ \\
\hline Significado vinculado às representações visuais & 79 & 14 & 5 & 98 \\
Significado indissociável de representações visuais & 0 & 2 & 1 & 3 \\
Significado sem relação sensorial & 0 & 1 & 0 & 1 \\
Total vertical & 79 & 17 & 6 & 102 \\
\hline
\end{tabular}

A Tabela 2 explicita as estruturas empírica e semântico-sensorial das linguagens geradoras de dificuldades comunicacionais ao aluno (A), suas relações e respectivas quantidades.

Tabela 2. Dificuldades de comunicação inerentes ao aluno (A): estruturas empírica e semântico-sensorial das linguagens.

\begin{tabular}{lcccc}
\hline \multicolumn{1}{c}{$\begin{array}{c}\text { Empírica (direita) } \\
\text { Semântico-sensorial (abaixo) }\end{array}$} & $\begin{array}{c}\text { Audiovisual } \\
\text { interdependente }\end{array}$ & $\begin{array}{c}\text { Auditiva e visual } \\
\text { independentes }\end{array}$ & $\begin{array}{c}\text { Fundamental } \\
\text { auditiva }\end{array}$ & $\begin{array}{c}\text { Total } \\
\text { horizontal }\end{array}$ \\
\hline Significado vinculado às representações visuais & 79 & 14 & 5 & 98 \\
Significado sem relação sensorial & 0 & 1 & 0 & 1 \\
Total vertical & 79 & 15 & 5 & 99 \\
\hline
\end{tabular}

Tomando por base os dados das Tabelas 1 e 2, apresentam-se as linguagens geradoras de dificuldade comunicacional aos alunos com deficiência visual. Estas linguagens encontram-se definidas a partir da relação: estrutura empírica/estrutura semântico-sensorial. Observa-se que, para exemplificar uma determinada linguagem, foram transcritos trechos oriundos das atividades do grupo de mecânica. Esclarece-se que as siglas (L) e (A-V) representam, respectivamente, declarações dos licenciandos e dos alunos videntes.

\section{Linguagem 1: Audiovisual interdependente/} significado vinculado às representações visuais

A presente linguagem foi a mais frequente, representando $77,4 \%$ das dificuldades de comunicação inerentes ao aluno (B) e 79,8\% das dificuldades inerentes ao aluno (A). Caracteriza-se pelo fato de veicular, por meio de códigos auditivos e visuais interdependentes, signi- 
A comunicação como barreira à inclusão ...

ficados vinculados às representações visuais. Contêm exemplos dessa linguagem os trechos de 1 a 5 :

\title{
Trecho 1
}

"L: soma de vetores seria assim, aqui você coloca o vetor $A$, aqui o $B$, e o soma está aqui ó, ele é a soma de A mais B."

O Trecho 1 apresenta a realização de uma soma vetorial gráfica. Para tal, o licenciando registrou na lousa os módulos, direções e sentidos dos vetores a e b e do vetor soma ( b). Nesse processo, representam-se o vetor a, o vetor b (origem na extremidade de a) e o vetor soma (origem na origem de a e extremidade na extremidade de b). Note-se que a estrutura empírica da linguagem não permite aos alunos com deficiência visual terem acesso às informações veiculadas: "aqui você coloca o vetor $A$, aqui o $B$, e o soma está aqui ó". Observando o trecho transcrito, a seguinte questão seria pertinente: aqui aonde? Fica claro que a resposta a tal questão encontra-se na componente visual da linguagem, componente esta inacessível aos alunos com deficiência visual.

\section{Trecho 2}

\author{
'L: A direção de um vetor é se ele está na horizontal, na vertical \\ desenha \\ L: mas falar horizontal e vertical é muito pouco porque e se ele estiver na diagonal? \\ L: Mas ele pode estar aqui, aqui, então tem que dar um jeito de medir, então mede \\ com ângulo \\ L: esse ângulo aqui, esse é o ângulo que o vetor forma com a horizontal mas fica a \\ seu critério a escolba"
}

O Trecho 2 enfoca as características da direção de um vetor. Em tal enfoque, o licenciando utilizou-se de linguagem de estrutura empírica audiovisual interdependente que mostrou-se insuficiente para a descrição da posição do vetor e do ângulo que o mesmo forma com a horizontal. Notem-se os fragmentos: "ele pode estar aqui, aqui", "esse ângulo aquii". Esses fragmentos evidenciam as funções assumidas pelas componentes auditiva e visual da estrutura empírica aqui analisada. Essas funções, são, respectivamente, indicativa e demonstrativa, ou seja, o código auditivo é empregado como indicador de objetos, posições, localizações, enquanto o código visual tem por finalidade descrever as características dos objetos, posições etc.

\section{Trecho 3}

"L: o que seria a equação de um objeto acelerado uniformemente?

L: ele está numa posição inicial no tempo zero, e a velocidade dele vai aumentando linearmente, é esta equação da aceleração

L: se eu colocar o eixo do tempo inicial como zero, vai ser $v$ menos $v$ zero sobre $t$ menos zero

L: então fica $v$ igual a $v 0$ mais a.t. 
L: a velocidade inicial que é o v0 nada impede que ela seja zero, o a.t que é a segunda componente aqui é esse tamanho aqui que o que seria?

$L: A$ variação da velocidade v menos v0 que o objeto sofreu num tempo $t$

L: eu acho que vocês já viram a equação x é igual a $x 0$ mais v0t mais meio de a.t quadrado

L: se en isolar o t nesta daqui e jogar nesta daqui en vou ter, o x0 continua, mais $v 0 t$, que vai ser $v$ menos $v 0$ dividido por a, mais meio de a t quadrado, $v$ menos $v 0$ sobre a ao quadrado

$L$ : mexendo nesta equação ai eu vou ter aquela $L a$ "

O Trecho 3 relata a demonstração de duas equações do movimento uniformemente variado, a equação da velocidade em função do tempo $\left(V=V_{0}+\right.$ a.t $)$ e a equação de Torricelli $\left(\mathrm{V}^{2}=\mathrm{V}_{0}^{2}+2\right.$ a.x). No processo de comunicação, o licenciando, utilizando-se da lousa, apresentou informações orais (basicamente indicativas) e visuais (basicamente demonstrativas) articuladas de forma interdependente: "é esta equação da aceleração" , "o a.t que é a segunda componente aqui é esse tamanho aqui", "se eu isolar o t nesta daqui e jogar nesta daqui", "mexendo nesta equação ai eu vou ter aquela la". O acesso às informações veiculadas por linguagens de estrutura empírica audiovisual interdependente somente pode se dar com a observação simultânea dos códigos auditivo e visual que atuam como suporte material. Dessa forma, os alunos com deficiência visual estiveram impossibilitados de participar do processo comunicacional aqui analisado.

\section{Trecho 4}

'L: se eu tenho aqui um plano inclinado, eu tenho o objeto sobre o plano e a força de atrito e a força normal ao plano desenha o plano e os vetores

L: eu tenho aqui um plano inclinado, ai tem uma força peso, eu faço aqui a decomposição de vetores

L: este p aqui vai ser igual a massa vezes a aceleração do corpo, en calculo a aceleração do corpo

L: se eu tiver uma superficie assim vai ficar complicado, pois em cada ponto da superficie vai ter uma decomposição diferente

L: a física vai trabalhar isto por meio do conceito de energia, eu não preciso fažer toda esta decomposição de vetores complicada aqui"

A decomposição do vetor peso em um plano inclinado é enfocada no Trecho 4. A partir de tal decomposição, visou o licenciando obter a aceleração do objeto posicionado sobre o plano. Novamente, o emprego de linguagem de estrutura empírica audiovisual interdependente mostrou-se inadequado para a veiculação das informações inerentes à decomposição vetorial, já que as funções indicativa e demonstrativa encontraram-se fragmentadas nas linguagens auditiva e visual. Ao final do trecho, o licenciando parece ter enfocado outro tipo de superfície: "se eu tiver uma superfície assim vai ficar complicado, pois em cada ponto da superfície vai ter uma decomposição diferente". Esta nova superfície parece ser curva, embora suas reais características estejam descritas na componente visual da linguagem. 
A comunicação como barreira à inclusão ...

\section{Trecho 5}

'L: Para calcular o trabalho de uma força elástica eu tenho que calcular a área abaixo da curva neste gráfico

L: O trabalho deve ser calculado desta forma porque a força aplicada na mola não é constante"

O Ttrecho 5 relata a explicação do licenciando acerca de como obter o trabalho realizado por uma força elástica. Argumentou que o trabalho pode ser obtido por meio do cálculo da área abaixo da curva de um determinado gráfico. As características do gráfico encontravam-se descritas em seu registro na lousa, registro este que somente podia ser observado visualmente. Portanto, as informações inerentes ao gráfico e à área foram inacessíveis aos alunos com deficiência visual.

Em linhas gerais, uma característica peculiar da presente linguagem é a de que o licenciando indica oralmente determinado aspecto visual registrado. Essa linguagem é comumente apoiada por recursos instrucionais do tipo: lousa, data show, retroprojetor.

\section{Linguagem 2: Auditiva e visual independentes/} significado vinculado às representações visuais

Representou 13,7\% das dificuldades comunicacionais do aluno (B) e 14,1\% das dificuldades do aluno (A). Como a presente linguagem veicula de forma independente informações auditivas e visuais de significados vinculados às representações visuais, o nível do detalhamento oral desses significados foi insuficiente para o acesso, por parte dos alunos com deficiência visual, às informações veiculadas. Na sequência, apresenta-se um exemplo do perfil linguístico abordado.

\section{Trecho 6}

"L: essa daqui é a equação da elipse, $x$ ao quadrado sobre $b$ ao quadrado mais $y$ ao quadrado sobre a ao quadrado é igual a um."

$\mathrm{O}$ Trecho 6 refere-se à apresentação da equação da elipse $\left(\mathrm{X}^{2} / \mathrm{A}^{2}+\mathrm{Y}^{2} / \mathrm{B}^{2}=1\right)$. Ao projetar, por meio de uma data show, a referida estrutura matemática (linguagem visual), o licenciando repetiu oralmente tal equação utilizando-se de uma expressão característica das potências, ou seja, "uma certa letra elevada a uma certa potência". É importante destacar que o registro gráfico de uma potência possui a seguinte estrutura visual: dois números (ou uma letra e um número), um pequeno e um grande localizados, respectivamente, na parte inferior e superior da estrutura. Esta representação dá-se em função de elementos visuais, o que implica dizer que quem codifica a informação de uma potência espera que o decodificador seja capaz de efetuar a decodificação por meio da representação visual. Este fato reflete-se na expressão verbal do referido código, na medida em que reproduz oralmente aquilo que é visível. Exemplos: dez elevado à quarta, a elevado ao cubo, b elevado ao quadrado. Para um aluno cego, as seguintes questões seriam pertinentes: o que foi elevado? É um cubo? É um quadrado? O dez está na parte de cima da quarta? Observa-se que notações de potências em braile não seguem 
a estrutura de "algo elevado a algo". Em braile, essas notações ocorrem horizontalmente, e, portanto, a palavra "elevado", que descreve de forma oral um registro visual, não faz sentido para alunos com deficiência visual.

\section{Linguagem 3: Fundamental auditiva/} significado vinculado às representações visuais

A presente linguagem foi responsável por $4,9 \%$ das dificuldades de comunicação inerentes ao aluno (B) e 5,0\% das dificuldades do aluno (A). Veicula por meio de códigos auditivos significados vinculados às representações visuais. Em outras palavras, os licenciandos falavam acerca de registros ou esquemas conhecidos apenas pelos alunos videntes. $\mathrm{Na}$ sequência, é apresentado um exemplo dessa linguagem.

\section{Trecho 7}

"L: então você tem cinco de força dividido por um, a pressão é cinco de força sobre um $c m$ dois"

O Trecho 7 descreve o licenciando efetuando, junto aos alunos com deficiência visual, o cálculo de pressão. Destaca-se como aspecto gerador de dificuldade comunicacional a forma como a unidade de área foi expressada, ou seja, "c $\mathrm{m}$ dois" $\left(\mathrm{cm}^{2}\right)$. O que teria representado para os alunos com deficiência visual o termo: "c $\mathrm{m}$ dois"? Teriam eles relacionado o mencionado termo ao significado que o mesmo busca comunicar, isto é, ao da área de um quadrilátero?

\section{Linguagem 4: Auditiva e visual independentes/} significado indissociável de representações visuais

Responsável por 2,0\% das dificuldades comunicacionais do aluno (B), caracteriza-se por veicular simultaneamente por meio dos códigos auditivo e visual, significados com a característica semântico-sensorial mencionada. Foi verificada em situações em que o licenciando projetava e descrevia oralmente frases contendo significados indissociáveis de representações visuais. Como exemplo, apresenta-se o Trecho 8.

\section{Trecho 8}

"L: ai vem esta frase que eu acho muito bacana o Newton ter escrito, ter deixado que é a seguinte: "se enxerguei além dos outros é porque estava no ombro de gigantes".

Pelo fato de ter sido projetada e lida ao mesmo tempo, a declaração de Newton, explicitada no trecho 8, refere-se a linguagem de estrutura empírica auditiva e visual independentes. Tal declaração, indica a ideia que Newton fez do conhecimento que construiu, isto é, um conhecimento fundamentado e melhor estruturado do que os produzidos por seus antecessores. Utilizando-se de analogia, relacionou o conhecimento por ele construído ao "enxergar mais longe" sem negar a base fundamentadora da nova forma de saber: "É porque estava no ombro de gigantes". A relação entre conhecer e ver indica a influência do elemento "visão" 
A comunicação como barreira à inclusão ...

na representação do ato de conhecer, ou seja, exprime o significado indissociável de representações visuais "conhecer é ver". Como pessoas cegas de nascimento, como é o caso do aluno $\mathrm{B}$, interpretam este tipo de significado? Com certeza, de forma diferente daquelas que pessoas videntes ou que perderam a visão ao longo da vida interpretam, pois, os cegos de nascimento não possuem representações ou ideias visuais para fundamentarem suas interpretações.

Linguagem 5: Fundamental auditiva/ significado indissociável de representações visuais

Representou 1,0\% das dificuldades comunicacionais do aluno (B). Como veicula informações por meio de códigos auditivos, as dificuldades dela originadas devem-se exclusivamente à estrutura semântico-sensorial dos significados enfocados. O trecho 9 exemplifica o emprego da linguagem em questão

\section{Trecho 9}

"L: quais são os tipos de energias que vocês conbecem? A-v: luminosa"

Como resposta à questão "quais são os tipos de energias que vocês conbecem?", um dos alunos videntes afirmou: "luminosa". Este diálogo, que ocorreu tendo como pano de fundo uma linguagem de estrutura empírica fundamental auditiva, enfocou um tema de significado indissociável de representações visuais, ou seja, a luz. Existe, para a ideia de luz, significado ligado estritamente às representações visuais e que não podem ser comunicados a alunos cegos de nascimento.

Em linhas gerais, uma característica peculiar da presente linguagem é a de que os interlocutores recorrem a "imagens visuais mentais". Isto implica dizer que objetos, situações, experiências etc., abordados durante a aula, não se encontram presentes ou registrados. Por esse motivo, essa linguagem não utiliza o apoio de recursos instrucionais para projetar algum tipo de imagem ou situação. Essas imagens e situações encontram-se projetadas nas "cabeças" dos alunos videntes e do aluno que perdeu a visão ao longo da vida.

\section{Linguagem 6: Auditiva e visual independentes/ \\ significado sem relação sensorial}

Responsável por 1,0\% das dificuldades comunicacionais dos alunos (A) e (B), veicula, por meio de códigos auditivos e visuais independentes, significados sensorialmente não relacionáveis, ou seja, que não se estruturam em representações sensoriais. Na sequência, um exemplo desse perfil linguístico é apresentado.

\section{Trecho 10}

\section{"L: então o intervalo de tempo delta t vai ser o t2 menos o $t$ "}

Nesse perfil linguístico, as informações são projetadas e lidas simultaneamente (estrutura empírica auditiva e visual independentes). Como o significado veiculado não possui 
relacionabilidade sensorial (especificamente a ideia ligada a intervalo de tempo), as dificuldades decorrentes deste perfil linguístico não estão associadas ao aspecto semântico-sensorial, e sim ao empírico. Dessa forma, devem-se ao detalhamento oral insuficiente das informações veiculadas.

A Tabela 3 explicita sinteticamente as linguagens geradoras de dificuldades comunicacionais, a característica peculiar da linguagem (se houver), suas porcentagens, bem como o recurso instrucional mais frequente em cada uma delas.

Tabela 3. Linguagens geradoras de dificuldades de comunicação.

\begin{tabular}{|c|c|c|c|c|}
\hline Linguagem & $\begin{array}{l}\text { Porcentagem } \\
\text { (B) }\end{array}$ & $\begin{array}{l}\text { Porcentagem } \\
\text { (A) }\end{array}$ & $\begin{array}{l}\text { Característica } \\
\text { peculiar }\end{array}$ & $\begin{array}{l}\text { Recurso } \\
\text { instrucional mais } \\
\text { empregado }\end{array}$ \\
\hline $\begin{array}{l}\text { L1: Audiovisual interdependente/significado } \\
\text { vinculado às representações visuais }\end{array}$ & $77,4 \%$ & $79,8 \%$ & $\begin{array}{l}\text { Indicar oralmente } \\
\text { registros visuais }\end{array}$ & $\begin{array}{l}\text { Lousa, data show, } \\
\text { retroprojetor }\end{array}$ \\
\hline $\begin{array}{l}\text { L2: Auditiva e visual independentes/ } \\
\text { significado vinculado às representações } \\
\text { visuais }\end{array}$ & $13,7 \%$ & $14,1 \%$ & $\begin{array}{l}\text { Detalhamento oral } \\
\text { insuficiente }\end{array}$ & $\begin{array}{l}\text { Lousa, data show, } \\
\text { retroprojetor }\end{array}$ \\
\hline $\begin{array}{l}\text { L3: Fundamental auditiva/significado } \\
\text { vinculado às representações visuais }\end{array}$ & $4,9 \%$ & $5,0 \%$ & $\begin{array}{l}\text { Recorrência a } \\
\text { representações dos } \\
\text { alunos videntes de } \\
\text { significados } \\
\text { visualmente } \\
\text { vinculados }\end{array}$ & Não utilizado \\
\hline $\begin{array}{l}\text { L4: Auditiva e visual independentes/ } \\
\text { significado indissociável de representações } \\
\text { visuais }\end{array}$ & $2,0 \%$ & 0 & $\begin{array}{l}\text { Som não veicula } \\
\text { significados } \\
\text { visualmente } \\
\text { indissociáveis }\end{array}$ & $\begin{array}{l}\text { Retroprojetor, data } \\
\text { show }\end{array}$ \\
\hline $\begin{array}{l}\text { L5: Fundamental auditiva/significado } \\
\text { indissociável de representações visuais }\end{array}$ & $1,0 \%$ & 0 & $\begin{array}{l}\text { Recorrência a } \\
\text { "imagens visuais } \\
\text { mentais" }\end{array}$ & Não utilizado \\
\hline $\begin{array}{l}\text { L6: Auditiva e visual independentes/ } \\
\text { significado sem relação sensorial }\end{array}$ & $1,0 \%$ & $1,0 \%$ & $\begin{array}{l}\text { Detalhamento oral } \\
\text { insuficiente }\end{array}$ & $\begin{array}{l}\text { Lousa, } \\
\text { retroprojetor, data } \\
\text { show }\end{array}$ \\
\hline
\end{tabular}

\section{Alternativas e conclusão}

Como conclusão, serão apresentadas e discutidas cinco alternativas de superação das dificuldades de comunicação. As alternativas destinam-se a indicar condições para a participação efetiva (de inclusão) do aluno com deficiência visual em aulas de mecânica. Fundamentarse-ão nas condições de acessibilidade do aluno mediante a consideração de sua potencialidade sensorial e a destituição das barreiras comunicacionais inerentes às estruturas empírica e semântico-sensorial das linguagens identificadas. 
1 Os significados vinculados às representações visuais representaram a principal barreira comunicacional a ser superada no contexto do ensino de mecânica e da deficiência visual (presentes em 96,1\% das dificuldades inerentes ao aluno B e em 99,0\% das dificuldades do aluno A). Esses significados não mantêm associação indissociável entre objeto de conhecimento e representação mental visual, e sim, vínculo entre objeto de conhecimento e representação mental visual. Dito de outro modo, significados visualmente vinculados são tornados externamente visíveis de modo a permitir sua comunicação. Entretanto, é perfeitamente possível a associação desses significados à representações não-visuais, procedimento este que viabilizaria sua veiculação por meio de códigos táteis, auditivos etc. Portanto, no contexto do ensino de mecânica para alunos com deficiência visual, vincular significados às representações não visuais seria um procedimento a ser adotado.

2 Outro tipo de estrutura bastante frequente nas atividades de mecânica refere-se à audiovisual interdependente. Esta estrutura empírica, responsável por 77,4\% das dificuldades comunicacionais do aluno (B) e por 79,8\% das dificuldades do aluno (A) impede a participação efetiva de discentes com deficiência visual junto aos processos comunicativos desenvolvidos no interior da sala de aula. Tal impedimento fundamenta-se na interdependência dos códigos auditivo e visual e nas funções indicativa e demonstrativa que, respectivamente, os referidos códigos assumem durante a veiculação de informações. Dessa forma, tanto a interdependência quanto as funções indicativa e demonstrativa impõem simultaneidade à observação dos códigos auditivo e visual. Em outras palavras, privado de uma das percepções sensoriais mencionadas, o discente não tem acesso ao significado abordado. Portanto, em relação à superação de dificuldades comunicacionais provenientes de estrutura empírica audiovisual interdependente, duas ações são fundamentais: (a) desfazer a interdependência dos códigos auditivo e visual que servem como suporte material; (b) atribuir ao código auditivo a função demonstrativa. Essas ações proporcionam um melhor detalhamento oral dos significados que se buscam comunicar, e, consequentemente, acesso adequado, por parte de alunos com deficiência visual, aos referidos significados.

3 A partir da descrição de dificuldades nos itens 1 e 2, fica justificado que a linguagem audiovisual interdependente/significado vinculado às representações visuais é totalmente inadequada à participação efetiva de alunos com deficiência visual em aulas de mecânica. Esta linguagem veicula significados vinculados às representações visuais por meio de códigos auditivos e visuais interdependentes. As dificuldades dela originadas poderiam ser resumidas da seguinte maneira: (1) docente registra ou projeta o objeto de comunicação (significado vinculado às representações visuais); (2) indica oralmente particularidades ou propriedades do objeto de comunicação. Não obstante, este perfil linguístico foi o responsável pela grande maioria das dificuldades comunicacionais dos alunos com deficiência visual (77,4\% das dificuldades do aluno B e 79,8\% das dificuldades do aluno A). Portanto, é prudente, ao docente de física, observar se não está utilizando, com frequência, este tipo de linguagem, pois ela é geradora de exclusão do discente com deficiência visual presente em aulas de mecânica.

4 Observou-se que o enfoque, em aulas de mecânica, dos significados indissociáveis de representações visuais foi secundário (2,9\% das dificuldades do aluno B). Este é um resultado importante, já que significados desta natureza tendem a convergir à vinculação, e não à indissociabilidade visual. Também observou-se que esses significados não foram inacessíveis ao aluno que perdeu a visão ao longo da vida, visto que, durante o período que enxergou (24 
anos), este discente teve a oportunidade de construir representações visuais de tais significados. Ainda, não foi verificada a associação entre significados visualmente indissociáveis e estrutura empírica audiovisual interdependente. Tal associação inviabilizaria o acesso do aluno (A) às informações veiculadas. Portanto, para alunos cegos de nascimento, significados indissociáveis de representações visuais são inacessíveis independentemente da estrutura empírica da linguagem empregada. Já aos alunos que perderam a visão ao longo da vida, tal inacessibilidade estará associada ao perfil da estrutura empírica empregada para a veiculação das informações.

5 A priori, significados sem relação sensorial não deveriam estar associados às dificuldades comunicacionais de alunos cegos (como é a ideia de intervalo de tempo cuja representação independe de ideias sensoriais). Dificuldades oriundas de significados sensorialmente não relacionáveis devem-se exclusivamente às características empíricas da linguagem. No caso das atividades de mecânica, essas características estiveram associadas à descrição oral insuficiente da estrutura empírica auditiva e visual independente que serviu como suporte material para a veiculação dos referidos significados.

Finalizando, as linguagens explicitadas atuaram como barreira comunicacional entre os alunos com deficiência visual, seus colegas videntes e os licenciandos. Esta barreira fez com que os discentes cegos, embora presentes na sala de aula, não tivessem acesso às informações veiculadas. Por isto, a criação de canais comunicacionais adequados os incluiria junto a processos intrínsecos de ensino/aprendizagem, tais como: a criação de hipóteses, a elaboração de dúvidas, reformulação e construção de conhecimentos etc. Sem a utilização de canais comunicacionais adequados, alunos com deficiência visual encontrar-se-ão numa condição de exclusão no interior da sala de aula. A comunicação representa, portanto, a variável central para a ocorrência de inclusão escolar de alunos com deficiência visual. A partir da construção de um ambiente comunicacional adequado, esses alunos terão condições estruturais básicas de participação efetiva junto aos processos de ensino/aprendizagem de mecânica. 
A comunicação como barreira à inclusão ...

\section{Referências}

BAJO, M.; CAÑAS, J. Las imágenes mentales. In: VARGAS, J. R. (Org.). Psicología de la memoria. Madrid: Alianza Editorial, 1991. p. 267-288.

BARDIN, L. Análise de conteúdo. Lisboa: Edições 70, 1977.

BRASIL. Congresso Nacional. Lei n. 9.394, de 20/12/1996. Fixa diretrizes e bases da educação nacional. Diário Oficial da República Federativa do Brasil, Brasília, n. 248, de 23 dez. 1996.

CAMARGO, E. P. A formação de professores de física no contexto das necessidades educacionais especiais de alunos com deficiência visual: o planejamento de atividades de ensino de física. 2006. 120f. Relatório final (Pós-Doutorado em Educação Para a Ciência) - Faculdade de Ciências, Universidade Estadual Paulista, Bauru, 2006.

O ensino de física no contexto da deficiência visual: elaboração e condução de atividades de ensino de física para alunos cegos e com baixa visão. 2005. 272f. Tese (Doutorado em Educação) - Faculdade de Educação, Universidade Estadual de Campinas, Campinas, 2005.

Um estudo das concepções alternativas sobre repouso e movimento de pessoas cegas. 2000. 218f. Dissertação (Mestrado em Educação para a Ciência) Faculdade de Ciências, Universidade Estadual Paulista, Bauru, 2000.

DIMBLERY, R.; BURTON, G. Mais do que palavras: uma introdução à Teoria da Comunicação. 4. ed. São Paulo: Cortez, 1990.

EISENCK, M.; KEANE, M. Cognitive psychology: a student's handbook. London: Erlbaum, 1991.

LACUEVA, A. La evaluación en la escuela: una ayuda para seguir aprendiendo. Revista da Faculdade de Educação da USP, São Paulo, v. 23, n. 1, p. 124-148, 1977.

MANTOAN, M. T. E. Inclusão escolar: o que é? Por quê? Como fazer? São Paulo: Moderna, 2003.

MARTINO, L. C. De qual comunicação estamos falando? In: HOHLFELDT, A.; MARTINO, L. C.; FRANÇA, V. V. (Orgs.). Teoria da comunicação: conceitos, escolas e tendências. 5. ed. Petrópolis: Vozes, 2005. p. 11-25.

MITTLER, P. Educação inclusiva: contextos sociais. São Paulo: Artmed, 2003.

SASSAKI, R. K. Inclusão: construindo uma sociedade para todos. 5. ed. Rio de Janeiro: WVA editora, 1999.

VIGOTSKI, L. S. Fundamentos de defectologia: el niño ciego. In: Problemas especiales da defectologia. Havana: Editorial Pueblo y Educación, 1997. p. 74-87. 